Portland State University

PDXScholar

University Honors Theses

University Honors College

Spring 6-16-2021

\title{
Building a Leader's Identity on Social Media
}

Morningstar Dickson

Portland State University

Follow this and additional works at: https://pdxscholar.library.pdx.edu/honorstheses

Part of the Industrial and Organizational Psychology Commons, Leadership Studies Commons, and the Social Media Commons

Let us know how access to this document benefits you.

\section{Recommended Citation}

Dickson, Morningstar, "Building a Leader's Identity on Social Media" (2021). University Honors Theses.

Paper 1072.

https://doi.org/10.15760/honors.1098

This Thesis is brought to you for free and open access. It has been accepted for inclusion in University Honors Theses by an authorized administrator of PDXScholar. Please contact us if we can make this document more accessible: pdxscholar@pdx.edu. 


\title{
Building A Leader's Identity on Social Media
}

\author{
By Morningstar Dickson
}

An undergraduate honors thesis submitted in partial fulfillment of the requirements for the degree of

Bachelor of Arts

in

University Honors

and

Psychology

Thesis Advisor

Tori Crain, Ph.D.

Portland State University 2021 


\section{Building A Leader's Identity on Social Media}

\section{Introduction}

As of January 2021, there were 4.2 billion active social media users, which is equivalent to more than 53 percent of the world's total population (Kemp, 2021). This figure increased by over 490 million users in the past year (Kemp, 2021). Social media usage has largely intercepted our personal, social, and professional lives and is expected to increase yearly (Kemp, 2021). The emergence of social media in politics, and business branding highlights how social media is becoming an important tool.

According to The Harris Poll, 62 percent of consumers say that businesses that do not have a strong social media presence will not succeed in the long run and 91 percent of business executives anticipate their company's social media budget to increase over the next few years (Gronek, 2021). Social media is not only viable for the success of future businesses but also for political leaders. For example, presidential election victories for both former presidents Barack Obama and Donald Trump were attributed to their social media usage (Edelman Research, 2009; Stahl, 2016). Social media platforms allow leaders to share information quickly and efficiently with their followers, improving their management of any conflicts or confusions. It also allows leaders to open up dialogue between themselves and their followers, which can widen the range of gaining alternate and strategic ideas (Heavey, et al, 2020).

Social media platforms enable anyone to grow a large following, so this article defines a leader as any individual who influences others. Since leaders have such great influence, we hold them to a higher moral standard making leaders more likely to leave their personal identity out of their social media presence. However, being authentic and thinking intentionally about how to showcase a personal and professional identity is important for their effectiveness. A trend that is 
seen when constructing an identity on social media is that there is a challenge in meshing the professional and personal identity. However, followers preferred real-life identities to be fully represented on the web (Ruan, et al, 2020). Understanding the correct mix of professional and personal information on social media can be beneficial (Jiang \& Kulemeka, 2017; Ruan, et al, 2020).

Congresswoman, Alexandria Ocasio-Cortez has the most Twitter followers of any member of the House. AOC's content ranges from starting political discussions to voter information to fun clips of her dog. AOC shares both professional and personal content. Her platform allows her to influence national conversations and has led to the creation of her fandom, people who consume everything she says and does (Cillizza, 2020). Social media has a tangible impact on the influence users carry when they have a large enough following. However, it is unclear exactly how leaders like AOC, were able to craft their social media accounts to elicit trust from their followers and to be more effective.

Using the present scholarship on authentic leadership and identity construction the current paper will create a theoretical framework that will help leaders build their identities on social media. This paper provides a roadmap for how to integrate personal and professional identity in order to lead followers more effectively. I do this through the lens of authentic leadership because it would help balance a leader's true identity and allow them to maintain a trusting relationship with their followers. The theory of authentic leadership, according to Gardner (2011), is that it is the idea that "people in organizations can effectively lead, and follow, in a way that enables them to express their own unique identity and style". In this paper, I will first review the literature on authentic leadership and trust. Then, provide a theoretical model for how leaders can combine their personal and professional identity online. Finally, I will 
discuss the practical implications of the research to aid the construction of identity on social media.

\section{Authentic leadership}

Social media influences the construction of our identity on and off-line (Coad, 2017). For leaders, their perceived identity will affect the network and resources they may have access to, as well as their relationship with their followers. However, leaders may have trouble representing a whole well-rounded identity. In one study, student leaders discussed how leadership contracts, campus responsibilities, and supervisor expectations sometimes had a silencing impact on their true selves (Ahlquist, 2017). I argue that authentic leadership could be the best direction for social media usage and identity construction because it would address this silencing impact, as well as build a trusting relationship with their followers. Which should increase the leaders' influence and effectiveness.

Authentic leadership is a genuine and value-based leadership style (Gardner et al, 2011). An authentic leader is self-aware, trustworthy, and committed to organizational success. Authentic leadership recognizes the importance for a leader to self-reflect and be self-aware to improve. Identity is a key factor in establishing authentic leadership and plays a role in how individuals regulate others' perceptions of them (Leary \& Kowalski, 1990).

The starting points for authentic leadership and for building a public image begin with the Greek philosophy, "Know thyself". The goal is to identify genuine aspects of yourself that should be emphasized to other people (Criswell \& Campbell, 2008a). Ways to establish your true self are by using honesty, admitting to personal mistakes, staying true to personal values through behavior, and having self-awareness (Leroy et al, 2015). These different behaviors will create a 
well-rounded image of authenticity. A part of being an authentic leader is having the ability to be self-aware and to self-reflect. Leaders should evolve and improve. Feedback is crucial for that change and having stable self-esteem will allow leaders to remain open and be non-defensive to negative feedback (Leroy et al, 2015). Part of that evolution is incorporating, desired traits and skills that the leader may want, as well as their followers. To remain true to the goal of authenticity, according to Criswell and Campbell (2008a) the best way to accomplish that is to first recognize your current image, then to find what your desired image is, and then finally develop the skills to close the gap between the two.

Authentic leadership is essential to building trust between the leader and follower. Personality and humanness are indicators of effective leadership (Criswell \& Campbell, 2008a). Humanizing leaders help them become more accessible, which can lead to desirable professional networks, increase trust, and can help leaders balance work and life (Jiang, Luo \& Kulemeka, 2017). Research has also shown that followers feel personally connected with leaders, even in the absence of interactions, when leaders consistently provide reliable information and align with their values. This personal connection can lead to followers creating emotional bonds with leaders, which can lead to affective trust (Heavy et al, 2020). Authentic leadership is important for establishing the identity of the leader and the relationship between them and their followers.

\section{Trust}

Trust is the willingness to be vulnerable with others in the face of uncertainty, which is based on positive expectations regarding the other party's intentions or behaviors (Mishra \& Mishra, 2013). The two types of trust leaders should form with followers is cognitive and affective trust. Cognitive trust is formed based on the availability, reliability, and credibility of the information presented and affective trust is formed based on emotional bonds (Heavey et al, 2020). Trust 
enhances individual, team, and organizational performances and creates deeper and more loyal relationships, which have stronger resiliency in the face of crisis (Mishra \& Mishra, 2013). Researchers have found that trust in leadership is positively related to a variety of outcomes, including job, organizational citizenship behaviors, organizational commitment, and job satisfaction, and is negatively related to the intention to quit (Dirks \& Ferrin, 2002; Mayer \& Gavin, 2005). Trust is the key factor for leaders to build a strong bond between them and their followers.

According to Mishra and Mishra (2013), the four basic aspects that lead to individuals trusting leaders are reliability, openness, competence, and compassion. Reliability is the need for consistency between one's words and actions (Gabarro, 1987; Kirkpatrick \& Locke, 1991; McGregor, 1967; Ouchi, 1981). Openness is being honest about one's own experiences and having the willingness to listen to others (Ouchi, 1981). Competence is the abilities, skills, and knowledge needed to achieve an expected performance (Nooteboom, 2002). Compassion is empathy towards others and not taking an unfair advantage of them. Also, compassion is placing your interest at an equal level of importance of others (Cummings \& Bromiley, 1996; McGregor, 1967). The best way for a leader to show they are reliable, open, competent, and compassionate is by communicating with their followers honestly and authentically.

An interview done by Mishra and Mishra (2013) with Bob Lintz, a former General Motors plant manager, discussed his thoughts on openness and trust. Lintz stated that:

"You really have to have it in your inner soul or in your inner conscious about the type of person you are. Opening yourself up and displaying your weaknesses is not easy for a lot of people. If you're going to get people to trust you, you're going to have to open up to all of your strengths, weaknesses, and shortcomings 
and demonstrate a commitment to a change process to which you're trying to lead the organization. I just don't feel that you can fake it.” (p.20)

Lintz essentially uses an authentic leadership approach to create a trusting bond with his employees. By being vulnerable with others authentic leaders encourage others to be vulnerable with them, giving their followers the confidence that they will not be exploited and therefore leading them to have more trust in those leaders (Mishra \& Mishra, 2013). Authentic leaders avoid the risk of being perceived as being hypocritical because there are no gaps or differences that are perceptible between their words and their actions (Walumbwa et al, 2008). They are also perceived by others as being aware of their own and other's values and morals, which brings in the compassion aspect of building trust (Luthans \& Avolio, 2003). Authentic leadership is the foundation for successfully establishing a trusting relationship between a leader and their followers.

\section{Authentic Online Identity}

The theoretical framework (Figure 1) that will help leaders build their identities on social media is a combination of personal and professional identities along with audience desire and expectation to create an authentic online presence. Using an authentic leadership approach and integrating the aspects of the leader's personal and professional identities as well as incorporating the desires and expectations of their audience to create a fully represented true identity of the leader, would allow them to establish a trusting relationship with their followers to lead more effectively. 


\section{Figure 1}

Authentic Online Identity Conceptual Model

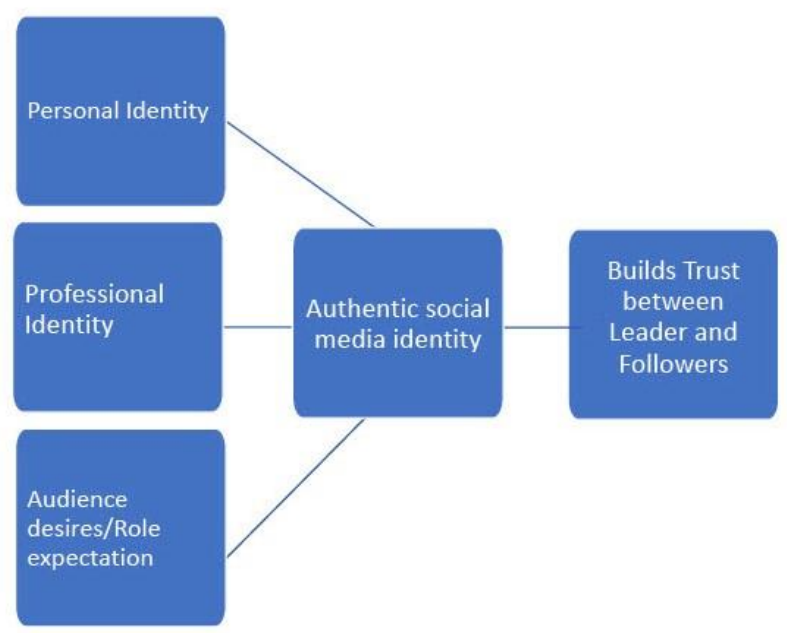

Personal identity

Personal identity and the idea of the self are the foundations for building an authentic identity online. It is constructed by one's internal values and morals and projects into the development of other identities (Ruan, et al, 2020). Individual or personal identity consists of a set of relatively stable characteristics that individuals ascribe to themselves, their narrative story, goals, beliefs, and values (Nagy \& Koles, 2014). A large part of the personal identity is the narrative story of a person. The self-narrative is what makes an action, experience, or characteristic properly attributed to a person (Rodogno, 2012). Everything begins with an understanding of the self. The self is a collection of identities drawn from role positions, which gives a person a sense of meaning and influences their behavior (Hogg et al, 1995).

Criswell and Campbell (2008b) found in their research, about identity in the workplace, that participants often forgot the professional details about people but could recall the personal 
information about them. On social media personal identity is seen through posts about the activities, events, opinions, interests, and relationships of an individual (Bossio, \& Sacco, 2017). A lot of social media content seems to be driven by individual personality, not an organizational brand. People prefer to follow individual, rather than institutional accounts (Bossio, \& Sacco, 2017; Sihi \& Lawson, 2018).

According to research done by Sihi and Lawson (2018), personal content can be used to make deeper connections with followers, provided an avenue for self-expression, and an effective way to humanize an organization or brand. Being personal is crucial in building a brand, however, authenticity is the key to the believability of this brand (Bossio, \& Sacco, 2017). Personal posts are viewed as authentic, original, and relatable, and posts that go along with industry trends can help establish credibility to the account (Sihi \& Lawson, 2018). Sharing personal experiences, stories, opinions, or beliefs was found to be the most common contributor to the perception of authenticity on online platforms (Sandlin \& Peña, 2014). The personal aspect of the account allows for more authentic dialogue between leaders and their followers (Sihi and Lawson, 2018). Being personal creates a vulnerability that is attractive to audiences.

\section{Professional Identity}

The development of digital identity is parallel to professional identity. Therefore, the origins of digital identity formation come from the perceived needs of an individual's professional roles (Ruan, et al, 2020). According to Bossio and Sacco (2017), professional identity is the understanding of the self in a professional context. Professional identity is how an individual behaves within the confines of a particular organization or profession. A representation of the professional identity online is important for individuals to find the right networks and community for their work. In a study done with graduate students, Coad (2017) 
found that students used social media, specifically Twitter to build a name- and face recognition in their academic discourse community.

The research shows that while most people choose to alter and shape their digital identities in online environments, tensions can arise when constructing these identities in professional contexts. Alquist (2017) brings up the concept of the silencing impact that professional organizations can have on their employees when it comes to their online identities. It seems that professional identity is more encouraged to be represented as opposed to a personal one. However, research has shown that people prefer real-life identity to be wholly represented on the web. Instances of misalignment resulted in identity conflict, compromising one of the identities (Ruan et al, 2020).

Jiang and Kulemeka's (2017) research showed that having a balance of professional and personal information on social media tends to establish mutually beneficial relationships. For example, in Bossio \& Sacco's (2017) study on Australian and American journalists, they found that the journalist who merged their professional and personal identities on social media saw it as an opportunity to engage with sources and audience members. These journalists used their personal online identities and connections to further enable their journalism. In these instances, the integration of professional and personal identity on social media became an essential tool for their work. In another study, some journalists used social media mainly as a professional communication tool but still opted to share several posts that represented their personal lives or interests, because it was difficult to separate the two as time went on (Bossio \& Holton, 2018). What both theses study found was that although participants initially preferred keeping personal and professional components separate their attempts to do so were inadequate; however, 
integration of both components allowed individuals to build better connections and have their identities fully represented.

Professional identity is constructed by the socialization and the expected roles of an individual's profession (Slay, \& Smith, 2010). Examples of this online would be likes, comments, and general traffic towards content. Individuals should modify the kind of content they post, based on the success of a certain kind of post and the general feedback they receive from others (Ruan, et al, 2020). Professional identity is formed by the professional roles demanded from an individual as well as the feedback they receive from their peers.

\section{Audience desires/ role expectation}

People construct and perform identity for a particular audience, therefore the representation of the self in online environments is influenced by the understanding and engagement with an audience (Bossio, \& Sacco, 2017). Since people construct and perform identity for a particular audience, identity is created within a context of sharing. However, Bossio and Sacco (2017) warn that creating content with a particular audience in mind can be seen as inauthentic. A leader can and should develop their skills to close the gap between their desired image and their current image to enhance their perceived authenticity (Criswell \& Campbell, 2008a). Therefore, it is important to consider the desired traits and skills that the followers may want when constructing the leader's identity.

The process of building a leadership image rest on prior expectations about the leader. Research shows that people try to ensure that their public image is consistent with the roles demanded by their situation. The failure to convey impressions that are consistent with one's roles can diminish one's effectiveness in that role (Leary \& Kowalski 1990). Impression 
management is influenced by self-concept, desired perceptions, role constraints, a leader's audience, and a leader's current and potential image (Leary \& Kowalski 1990). According to Just and Crigler (2000) reputation merges with personal traits, so much so that positive or negative evaluations can influence the perception of what is regarded as personal qualities of a leader. Therefore, it is beneficial for leaders to build an identity that is charismatic and responsive to the needs and interests of their audience (Khamis et al, 2017).

It is important to note that a person's potential to lead relies on the extent to which they are perceived by followers to embody the group's identity (Hogg et al, 2019). How people will respond to a leader depends on what social group they perceive the leader to be a part of, groups like nationality, heritage, gender, race, and other identity categories (Ruderman \& Ernst, 2010). Certain groups' identities are stigmatized, due to inequalities in our society. "A stigmatized cultural identity is one in which members of a group are assumed to be tainted or inferior" (Slay \& Smith, 2010, p.86). Consequently, if a leader is perceived to be a part of one of these groups it could prevent easy inclusion to other groups, which can affect their effectiveness to lead. When constructing your identity as a leader it is important to understanding your perceived identity.

\section{Discussion}

Social media has become an important aspect of our personal, social, and professional lives. An example of this is vital usage of it in politics and business branding. For leaders, social media platforms allow them to share information quickly and efficiently, improving their management of any conflicts and also allows leaders to open up dialogue between themselves and their followers (Heavey, et al, 2020). Since social media platforms enable anyone to grow a large following, this article defines a leader as any individual who influences others. Since leaders are held to higher moral standards, they are likely to suppress their personal identity online (Alquist, 
2017). However, being authentic and intentionally displaying a personal and professional identity online is important for their effectiveness. According to research done by Ruan et al (2020) followers prefer real-life identities to be fully represented on the web. So, it can be beneficial to understanding the correct mix of professional and personal information on social media (Jiang \& Kulemeka, 2017; Ruan, et al, 2020).

Authentic leadership is a leadership style that allows individuals to effectively lead in a way that enables them to express their unique identity and style (Gardner, 2011). Authentic leadership is to identify and emphasize genuine aspects of yourself to other people (Criswell \& Campbell, 2008a). Leaders who are more personable and humanized are more effective because it helps them become more accessible and desirable to professional networks, which increases trust. (Criswell \& Campbell, 2008b; Jiang, Luo \& Kulemeka, 2017). This paper argues that authentic leadership could be the best direction when constructing a leader's identity online because it would not only address the silencing impact professional organizations may have on the leader's personal identity, but also help build a trusting relationship between them and their followers. Trust is the key factor when building a strong bond between leaders and their followers. Trust is defined as the willingness to be vulnerable with others in the face of uncertainty (Mishra \& Mishra, 2013). Trust creates deeper and more loyal relationships and can enhance individual, team, and organizational performances (Mishra \& Mishra, 2013). Leaders should focus on forming two forms of trust with their followers, cognitive and affective trust. Cognitive trust is formed based on the reliability, availability, and credibility of information given by the leader. Affective trust is formed based on emotional bonds (Heavey et al, 2020).

This paper aims to integrate personal and professional identity, as well as the audience's desires and expectations, in order for leaders to lead followers more effectively and to create a more 
authentic online presence. Using an authentic leadership approach, this paper builds a theoretical framework (Figure 1) that combines these aspects of identity and expectations to create a fully represented true identity of the leader, which would allow them to establish a trusting relationship with their followers.

Personal identity is an individual's narrative story, goals, beliefs, and values, and a set of relatively stable characteristics that they ascribe to themselves (Nagy \& Koles, 2014). Personal posts, that share personal experiences, stories, opinions are viewed as authentic, original, and relatable (Sandlin \& Peña, 2014; Sihi \& Lawson, 2018). This vulnerability online encourages others to be vulnerable with the leader, leading them to have more trust in that leader (Mishra \& Mishra, 2013).

Identity is created within a context of sharing, and therefore construction and performance of identity are for a particular audience, so the representation of the self in online environments is influenced by the awareness of and engagement with an audience (Bossio, \& Sacco, 2017). A person's potential to lead relies on the extent to which they are perceived by followers (Hogg et al, 2019). Understanding impression management is vital for leaders to convey an image that is consistent with one's roles and identity. It is constructed by the self-concept, desired perceptions, role constraints, a leader's audience, and a leader's current and potential image (Leary \& Kowalski 1990). The best way to maintain authenticity, while considering an audience's desire and expectation of a leader is for leaders to develop the skills to become their desired image (Criswell and Campbell, 2008a).

Professional Identity is the understanding of the self in a professional context. How a person would behave within the confines of a particular profession and is constructed by the socialization and the expected roles of an individual's profession (Bossio, \& Sacco, 2017; Slay, 
\& Smith, 2010). Although digital identity is developed parallel to professional identity, research has shown that the integration of both personal and professional identity allows individuals to build better connections and have their identities fully represented online (Jiang \& Kulemeka, 2017; Ruan, et al, 2020).

\section{Practical implications}

Based on the research, personal posts are perceived as original, relatable, and authentic; and professional posts that follow industry trends help establish credibility (Sihi \& Lawson, 2018). Using humor and a personal opinion on post captions is a strategic way to self-promote (Bossio \& Holton, 2018). Posting images of everyday life, hobbies and activities brings more humanity to the posts, and using more lighthearted and intimate language rather than a professional one helps (Bossio \& Sacco, 2017). Criswell and Campbell (2008b) advise using inclusive language like "us" and "we" when addressing followers and to ensure there is consistency between what you say, what you do, and how you appear. However, a part of being human is not being able to promise consistency, so it is important, to be honest, admit personal mistakes, have self-awareness, and stay true to personal values through your behavior (Leroy et al, 2015). A way to stay open and self-aware is by having a willingness to listen to others and to place your interest at an equal level of importance of others (Mishra \& Mishra, 2013). Some helpful tips from professionals and researchers are to understand the importance of disconnecting and limiting social media usage. Disconnection can lead to less anxiety; help maintain a distinct representation of the self-online and may also help manage large audiences (Bossio \& Holton, 2018). Another important tip to consider is that the online world is permanent, so it is best to think of social media as a publishing platform (Bossio \& Sacco, 2017). Lastly, remember to disclose personal details and feelings, by sharing descriptive personal experiences, stories, 
opinions, and beliefs (Sandlin \& Peña, 2014). Having an authentic identity online is not about creating a perfect public image, but about representing yourself in an honest way that followers can relate to and trust. 


\section{References}

Ahlquist, J. (2017). Digital student leadership development. New Directions for Student Leadership,(153), 47-62. https://doi.org/10.1002/yd.20229

Barassi, Veronica, \& Zamponi, Lorenzo. (2020). Social media time, identity narratives, and the construction of political biographies. Social Movement Studies, 19(5-6), 1-17. https://doi.org/10.1080/14742837.2020.1718489

Bates, Adam, Hobman, Trish, \& Bell, Beth T. (2019). "Let me do what I please with it . . . don’t decide my identity for me": LGBTQ+ youth experiences of social media in narrative identity development. Journal of Adolescent Research, 35(1), 51-83. https://doi.org/10.1177/0743558419884700

Bossio, Diana, \& Holton, Avery E. (2018). The identity dilemma: Identity drivers and social media fatigue among journalists. Popular Communication, 16(4), 248-262. https://doi.org/10.1080/15405702.2018.1535658

Bossio, Diana, \& Sacco, Vittoria. (2017). From "selfies" to breaking tweets. Journalism Practice, 11(5), 527-543. https://doi.org/10.1080/17512786.2016.1175314

Cillizza, C. (2020). The absolutely remarkable social media power of Alexandria Ocasio-Cortez. CNN. https://www.cnn.com/2020/07/24/politics/aoc-ted-yoho-cspan/index.html.

Coad, D. T. (2017). “That's my face to the whole field!”: Graduate students' professional identity-building through Twitter at a writing studies conference. Computers and Composition, 45, 51-66. https://doi.org/10.1016/j.compcom.2017.06.003 
Criswell, C., \& Campbell, David. (2008a). Building an authentic leadership image (1st edition). Center for Creative Leadership.

Criswell, C., and Campbell, D., (2008b) "Image counts: Building an authentic leadership presence." Leadership in Action 28, 2, 13-17.

Cummings, L., \& Bromiley, P. (1996). The organizational trust inventory (OTI): Development and validation. Trust in organizations: Frontiers of theory and research (pp. 302- 330).

Dirks, K. T., \& Ferrin, D. L. (2002). Trust in leadership: Meta-analytic findings and implications for research and practice. Journal of Applied Psychology, 87, 618.

Edelman Research (2009) The social pulpit, p. 1.

Evelyn Lanka, Anna Topakas \& Malcolm Patterson (2020) Becoming a leader: Catalysts and barriers to leader identity construction, European Journal of Work and Organizational Psychology, 29:3, 377-390, DOI: 10.1080/1359432X.2019.1706488

Gabarro, J. (1987). The dynamics of taking charge. Boston, MA: Harvard Business School Press. (p.104)

Gardner, M. (2019). Episcopal leadership in the age of social media: Bishops determine how best to use social media platforms (EPISCOPAL LEADERSHIP). Anglican Journal, 145(3), 10.

Gronek, G. (2021). Businesses anticipate significant increase in social media investments as it becomes essential for long-term success. Street Insider. StreetInsider.com.

Heavey, C., Simsek, Z., Kyprianou, C., \& Risius, M. (2020). How do strategic leaders engage with social media? A theoretical framework for research and practice. Strategic 
Management Journal, 41(8), 1490-1527. DOI:

http://dx.doi.org.proxy.lib.pdx.edu/10.1002/smj.3156

Hogg, Michael A, Terry, Deborah J, \& White, Katherine M. (1995). A tale of two theories: A critical comparison of identity theory with social identity theory. Social Psychology Quarterly, 58(4), 255-269. https://doi.org/10.2307/2787127

Hogg, Michael A., Haslam, S Alexander., Rast III, E David., Steffens, Niklas K \& Gaffney, M Amber. (2019). Social identity and leadership. The Leadership Quarterly, 30(6), 101362. https://doi.org/10.1016/S1048-9843(19)30727-1

Jiang, Hua, Luo, Yi, \& Kulemeka, Owen. (2017). Strategic social media use in public relations: Professionals' perceived social media impact, leadership behaviors, and work-life conflict. International Journal of Strategic Communication, 11(1), 18-41. https://doi.org/10.1080/1553118X.2016.1226842

Kasperiuniene, Judita, \& Zydziunaite, Vilma. (2019). A systematic literature review on professional identity construction in social media. SAGE Open, 9(1), 215824401982884. https://doi.org/10.1177/2158244019828847

Kemp, S. (2021). Digital 2021: Global overview report - data reportable - global Digital insights. Retrieved April 12, 2021, from https://datareportal.com/reports/digital-2021global-overview-report

Khamis, Susie, Ang, Lawrence, \& Welling, Raymond. (2017). Self-branding, 'micro-celebrity', and the rise of Social Media Influencers. Celebrity Studies, 8(2), 191-208. 
Kirkpatrick, S., \& Locke, E. (1991). Leadership: Do traits matter? Academy of Management Executive, 5 (2), 48- 60.

Knight, Julia, \& Weedon, Alexis. (2014). Identity and social media. Convergence (London, England), 20(3), 257-258. https://doi.org/10.1177/1354856514536365

Leroy, Hannes, Anseel, Frederik, Gardner, William L, \& Sels, Luc. (2015). Authentic leadership, authentic followership, basic need satisfaction, and work role performance. Journal of Management, 41(6), 1677-1697. https://doi.org/10.1177/0149206312457822

Levy, Drorit, Shlomo, Shirley Ben, \& Itzhaky, Haya. (2014). The 'building blocks of professional identity among social work graduates. Social Work Education, 33(6), 744759. https://doi.org/10.1080/02615479.2014.883600

Luthans, F., \& Avolio, B. (2003). Authentic leadership development. In Cameron, Dutton, \& Quinn (Eds), Positive organizational scholarship: Foundations of a new discipline (pp. 240-258). San Francisco, CA: Berrett-Koehler.

Marion Just, \& Ann Crigler. (2000). Leadership image-building: After Clinton and Watergate. political psychology, 21(1), 179-198. https://doi.org/10.1111/0162-895X.00183

Mayer, R. C., \& Gavin, M. B. (2005). Trust in management and performance: Who minds the shop while the employees watch the boss? The Academy of Management Journal, 48 (5), $874-888$.

McGregor, D. (1967). The professional manager. New York: McGraw-Hill. 
Michael A Hogg, S Alexander Haslam, David E Rast III, Niklas K Steffens, \& Amber M Gaffney. (2019). Social identity and leadership. The Leadership Quarterly, 30(6), 101362. https://doi.org/10.1016/S1048-9843(19)30727-1

Mishra, A., \& Mishra, Karen E. (2013). Becoming a trustworthy leader: psychology and practice. Routledge.

Nagy, Peter, \& Koles, Bernadett. (2014). The digital transformation of human identity. Convergence (London, England), 20(3), 276-292. https://doi.org/10.1177/1354856514531532

Nooteboom, B. (2002). Trust: Forms, foundations, functions, failures, and figures. Cheltenham, U.K.: Edward Elgar.

Ouchi, William G. (1981) Theory Z: How American business can meet the Japanese challenge. Reading, MA: Addison-Wesley.

Phillip L. Hammack, \& Erin E. Toolis. (2015). Putting the social into personal identity: The master narrative as a root metaphor for psychological and developmental science. Human Development, 58(6), 350-364.

Quartz Marketing Team (2016). Quartz: Global Executive Study. https://insights.qz.com/ges/2016/.

Rodogno, Raffaele. (2012). Personal identity online. Philosophy \& Technology, 25(3), 309328. https://doi.org/10.1007/s13347-011-0020-0

Ruan, Brandon; Yilmaz, Yusuf; Lu, Daniel; Lee, Mark; \& Chan, Teresa M. (2020). Defining the digital self: A qualitative study to explore the digital component of professional identity 
in the health professions. Journal of Medical Internet Research, 22(9), e21416-e21416. https://doi.org/10.2196/21416

Ruderman, Marian N, \& Ernst, Christopher. (2010). Finding yourself how social identity affects leadership. Leadership in Action, 30(1), 14-18. https://doi.org/10.1002/lia.1321

Sandlin, Jean Kelso, and Peña, Edlyn Vallejo. Building authenticity in social media tools to recruit post-secondary students. Innovative Higher Education 39, 4 (2014): 333-46.

Schedlitzki, Doris, Edwards, Gareth, \& Kempster, Steve. (2018). The absent follower: Identity construction within organizationally assigned leader-follower relations. Leadership (London, England), 14(4), 483-503. https://doi.org/10.1177/1742715017693544

Sihi, Debika, \& Lawson, Kara. (2018). Marketing leaders and social media: Blending personal and professional identities. Journal of Marketing Theory and Practice, 26(1-2), 38-54. https://doi.org/10.1080/10696679.2017.1389240

Slay, Holly S, \& Smith, Delmonize A. (2010). Professional identity construction: Using narrative to understand the negotiation of professional and stigmatized cultural identities. Human Relations (New York), 64(1), 85-107. https://doi.org/10.1177/0018726710384290

Stahl, L. (2016) Trump says his social media power key to victory, CBS 60 minutes, Retrieved April 12, 2021, from https://www.cbsnews.com/news/president-elect-trump-says-socialmedia-played-a-key-role-in-his-victory/

Tomkins, L. (2020). Lost in translation, recovered in conversation? Leadership and social media. Leadership (London, England), https://doi.org/10.1177/1742715020959729 
Walumbwa, F. O., Avolio, B. J., Gardner, W. L., Wernsing, T. S., \& Peterson, S. J. (2008).

Authentic leadership: Development and validation of a theory based measure. Journal of Management, 34, 89- 126.

Leary, M. R., \& Kowalski, R. M. (1990). Impression management: A literature review and twocomponent model. Psychological Bulletin, 107(1), 34-47.

doi:http://dx.doi.org.proxy.lib.pdx.edu/10.1037/0033-2909.107.1.34 